\title{
Octopamine Modulates the Axons of Modulatory Projection Neurons
}

\author{
Jean-Marc Goaillard, David J. Schulz, Valerie L. Kilman, and Eve Marder \\ Volen Center and Biology Department, Brandeis University, Waltham, Massachusetts 02454
}

\begin{abstract}
Octopamine increases the cycle frequency of the pyloric rhythm in the crab Cancer borealis by acting at multiple sites within the stomatogastric nervous system. The junction between the stomatogastric nerve $(s t n)$ and the superior esophageal nerve (son) shows synaptic structures. When applied only to the stn-son junction, octopamine induced action potentials in the axons of the modulatory commissural neuron 5 (MCN5) that project from the commissural ganglia to the stomatogastric ganglion (STG). The activation of the MCN5 neurons was correlated with an increase in the pyloric rhythm frequency. Additionally, octopamine had direct effects on the STG, including the activation of the pyloric dilator and pyloric neurons, an increase in the pyloric frequency, and a change in the phase relationships of the pyloric neurons. Thus, the same modulator can influence the pyloric rhythm by acting at multiple sites, including the axons of identified modulatory neurons that project to the STG. These data demonstrate that axonal propagation may be influenced locally by neuromodulators acting on axonal receptors, therefore altering the conduction of information from different command and integrating centers.
\end{abstract}

Key words: central pattern generator; stomatogastric ganglion; crustaceans; crabs; neuromodulation; spike initiation; axonal synapse

\section{Introduction}

The activation and function of central pattern generating circuits in both invertebrate and vertebrate systems depend on neuromodulatory inputs. In numerous systems, descending neuromodulatory pathways that release various amines and neuropeptides act on elements of central pattern generating circuits to alter the intrinsic membrane properties of constituent neurons and the synaptic connections among them. As a consequence of neuromodulator action, central pattern generating networks are configured appropriately to produce behaviorally relevant motor patterns (Marder and Calabrese, 1996; Marder and Bucher, 2001).

A great deal of insight into the cellular mechanisms and target neurons underlying neuromodulation of central pattern generators has come from the exogenous application of neuromodulatory substances. Additional insight into how descending modulatory projection neurons reconfigure central pattern generating networks has come from direct electrophysiological investigations of the actions of these descending pathways (Nusbaum et al., 2001; Nusbaum and Beenhakker, 2002). That said, relatively little is known about the extent to which the descending pathways

Received Feb. 15, 2004; revised June 30, 2004; accepted July 1, 2004.

This work was supported by National Institutes of Health (NIH) Grant NS 17813 (E.M.), fellowship SPE20021213048 from the Fondation pour la Recherche Médicale (J.-M.G.), and NIH Grant 1 F32 MH70292 (D.J.S). We thank Dirk Bucher and Stefan Pulver for help with immunohistochemistry experiments and Cyrus Billimoria for stimulating discussions.

Correspondence should be addressed to Eve Marder, Brandeis University, Volen Center MS 013, Waltham, MA 02454-9110. E-mail:marder@brandeis.edu.

V. L. Kilman's present address: Neurobiology and Physiology, 2205 Tech Drive, Hogan 2-160, Northwestern University, Evanston, IL 60208.

D01:10.1523/JNEUROSCI.2078-04.2004

Copyright $\odot 2004$ Society for Neuroscience $\quad$ 0270-6474/04/247063-11\$15.00/0 themselves may be directly or indirectly modulated in different behavioral states. In this study, we demonstrate that octopamine can modulate the central pattern generating network of the pyloric rhythm of the crab stomatogastric ganglion (STG) both directly and indirectly by acting on the axons of an identified pair of descending modulatory projection neurons, the modulatory commissural neuron 5 (MCN5).

The STG receives modulatory inputs from at least three anterior ganglia, the single esophageal ganglion (OG), and the bilaterally paired commissural ganglia (CoGs). Together the OG and CoGs send $\sim 25$ pairs of descending axons into the single stomatogastric nerve (stn) that then enters the STG (Coleman et al., 1992). Many of these descending axons have now been identified, their cotransmitter complement defined, and their physiological actions characterized (Nusbaum and Beenhakker, 2002). The bilaterally paired MCN5 neurons excite the pacemaker neurons for the pyloric rhythm and inhibit other neurons of the pyloric network (Norris et al., 1996).

Many, if not all, of the known descending projection neurons to the STG are found as bilateral pairs, and their axons join together in the midline as they enter the stn at the junction of the esophageal nerve (on), the superior esophageal nerve (son), and the stn (Nusbaum and Beenhakker, 2002). Therefore, this site is special, because it is the first anatomical location at which bilaterally arising neuronal pathways can interact. Interestingly, numerous immunocytochemical studies have shown areas of what appear to be neuropilar-like varicosities and branches in this location (Marder et al., 1986, 1987; Kilman et al., 1999; Skiebe, 1999; Skiebe et al., 1999), and this is also a site at which synapses are seen (Kilman, 1998; Skiebe and Ganeshina, 2000; Skiebe and Wollenschlager, 2002). We now find that the axons of the MCN5 neurons are sensitive to octopamine at this site and that the ef- 


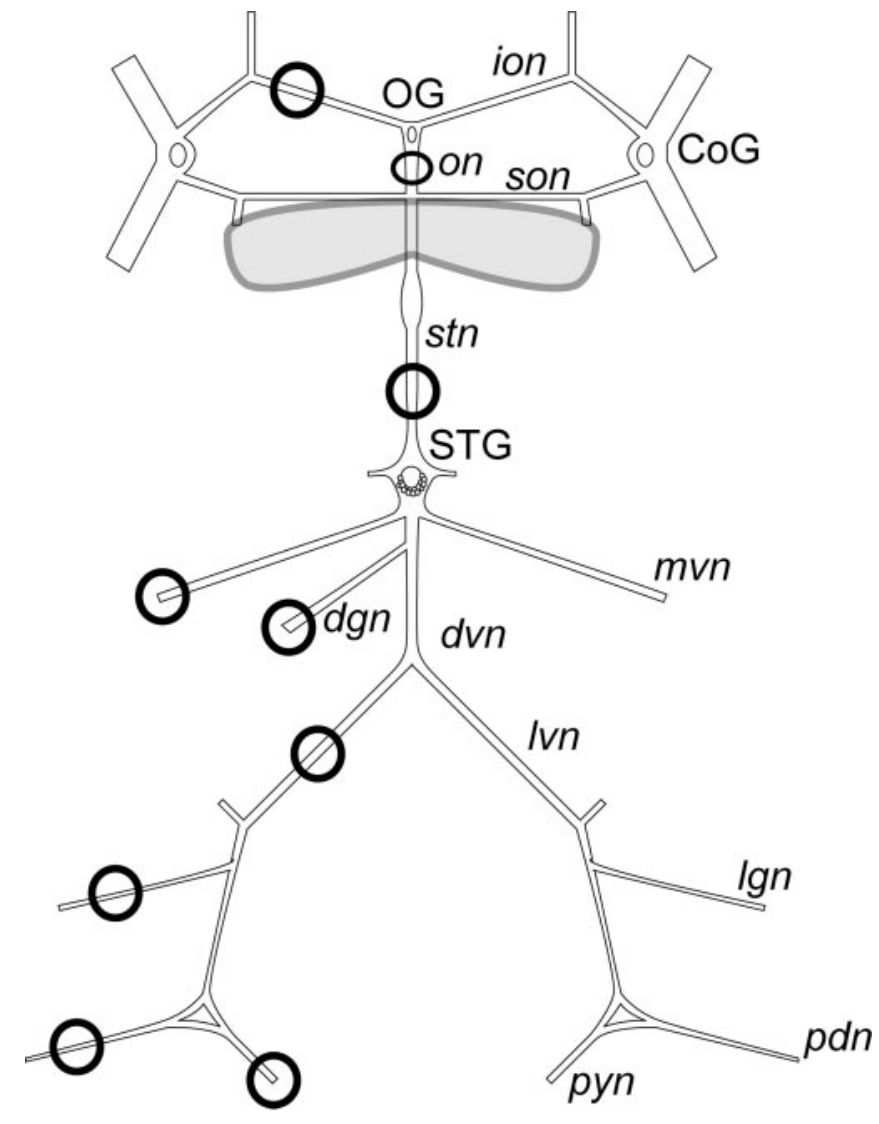

Figure 1. The stomatogastric nervous system of the crab C. borealis. Black rings indicate petroleum jelly wells used to record the activity of the different nerves, whereas the gray "bowtie" shape represents a superfusion well used transiently to apply drugs specifically to the stn-son junction. The latter and the stn well were also used to block stn impulse activity with $\Pi \mathrm{TX}$-sucrose.

fects of octopamine on the pyloric rhythm of the crab depend both on its actions on the STG itself and on the axons of the MCN5 neurons.

\section{Materials and Methods}

Adult crabs, Cancer borealis $(n=59)$, were obtained from Yankee Lobster (Boston, MA) and maintained in artificial seawater until used. Crabs were anesthetized by keeping them on ice for $30 \mathrm{~min}$ before dissection. The complete stomatogastric nervous system (STNS) (Fig. 1), consisting of the paired CoGs, the OG, the STG, and some of the motor nerves, was dissected out of the animal and pinned out in a Sylgard-coated (Dow Corning, Midland, MI) dish containing chilled $\left(9-13^{\circ} \mathrm{C}\right)$ saline. The physiological saline solution consisted of the following (in mM): $440 \mathrm{NaCl}, 11 \mathrm{KCl}, 13 \mathrm{CaCl}_{2}, 26 \mathrm{MgCl}_{2}, 11$ Trizma base, and 5 maleic acid, $\mathrm{pH} 7.45$.

Nerve dye-fills and immunohistochemistry. After dissection of the STNS, a petroleum jelly (Vaseline) well was placed on the inferior esophageal nerve (ion). After the nerve was cut, the physiological saline solution in the well was replaced consecutively by distilled water $(5 \mathrm{~min})$ and a Neurobiotin solution ( $5 \%$ in distilled water, $48 \mathrm{hr}$ ). The preparations were then fixed for $1-2 \mathrm{hr}$ in $4 \%$ paraformaldehyde in $0.1 \mathrm{~m}$ sodium phosphate buffer, $\mathrm{pH}$ 7.4, and then left overnight in $0.1 \mathrm{M}$ phosphate buffer, $\mathrm{pH}$ 7.4. The next day the preparations were washed four to five times over the course of 7-8 hr in PTA ( $0.1 \mathrm{~m}$ sodium phosphate buffer, $0.3 \%$ Triton $\mathrm{X}-100$, and $0.1 \% \mathrm{NaN}_{3}, \mathrm{pH}$ 7.4). Tissues were then incubated overnight with a rabbit polyclonal antibody raised against synaptotagmin I at a dilution of 1:1000 in PTA. The anti-synaptotagmin I antibody was a gift from Hugo Bellen (Baylor College, Houston, TX) and has been used previously to map presynaptic release sites in Drosophila (Littleton et al., 1993) and crustaceans (Skiebe and Wollenschlager,
2002). Preparations were then washed four to five times in PTA and incubated overnight in 1:400 anti-rabbit IgG coupled to AlexaFluor 488 (Molecular Probes, Eugene, OR) and 1:400 streptavidin coupled to Cy5 (Jackson ImmunoResearch, West Grove, PA). After secondary incubation, the preparations were washed five to six times in $0.1 \mathrm{~m}$ phosphate buffer and mounted on glass slides in methyl salicylate (Sigma, St. Louis, MO).

Imaging. Mounted preparations were viewed with the appropriate filters on a Leica TCS confocal microscope fitted with argon $(458 / 488 \mathrm{~nm})$ and krypton lasers $(568 \mathrm{~nm})$. Optical sections were taken every $1 \mu \mathrm{m}$. The resulting images were compiled into maximum projections in the three-dimensional reconstruction program Amira (TGS, San Diego, CA) and then processed with Canvas 9 (Deneba, Miami, FL).

Electron microscopy. For electron microscopy, the tissues were processed as described previously (Kobierski et al., 1987; Kilman and Marder, 1996). After fixation, the tissues were rinsed two to three times for $15-30 \mathrm{~min}$ and then postfixed for $1 \mathrm{hr}$ in $1-2 \% \mathrm{OsO}_{4}$ in $0.05 \mathrm{M}$ cacodylate buffer containing $0.5 \mathrm{M}$ sucrose and $2.5 \mathrm{~mm} \mathrm{CaCl}_{2}$. After a brief rinse in distilled water, some ganglia were stained en bloc in saturated aqueous uranyl acetate for $30 \mathrm{~min}$, and others were immediately dehydrated in alcohol, passed through propylene oxide (for Eponate 12 resin only), and embedded in Eponate 12 or Spurr's resin (both from Ted Pella). The resin blocks were polymerized at $70^{\circ} \mathrm{C}$ for $12-36 \mathrm{hr}$. The tissue was then sectioned $70-80 \mathrm{~nm}$ thick with a diamond knife, picked up on copper slot grids, laid onto prepared Formvar or pioloform film (Ted Pella), and stained with lead citrate and uranyl acetate. All grids were viewed on a Phillips 301 transmission electron microscope.

Electrophysiological recordings and pharmacological applications. For electrophysiological recordings, the STG was desheathed, and petroleum jelly wells were placed on the motor nerves (Fig. 1). Extracellular recordings from the nerves were made by placing stainless steel pin electrodes in the wells. Signals were amplified and filtered using a differential AC amplifier (A-M Systems, Carlsburg, WA). Intracellular recordings from the STG or CoG somata were made using 20-40 M $\Omega$ glass microelectrodes filled with $0.6 \mathrm{M} \mathrm{K}_{2} \mathrm{SO}_{4}$ and $20 \mathrm{~mm} \mathrm{KCl}$ and an Axoclamp $2 \mathrm{~A}$ (Axon Instruments, Foster City, CA). Pyloric motor neurons were identified using standard procedures for C. borealis (Hooper et al., 1986; Weimann et al., 1991). When appropriate, the STG was isolated from the CoGs and OG by blocking action potential conduction in the $s t n$ with 750 mM sucrose and $1 \mu \mathrm{M}$ TTX in a petroleum jelly well on the stn. During recordings, the preparations were superfused continuously with chilled $\left(9-13^{\circ} \mathrm{C}\right)$ control physiological saline or octopamine (Sigma) containing saline at indicated concentrations. The octopamine concentration was $10^{-4} \mathrm{M}$ unless stated otherwise. When octopamine or TTX was applied to the $s t n$, the nerve was desheathed to facilitate the access of drugs to the axonal membrane.

Data acquisition and analysis. Data were acquired using a Digidata 1200 data acquisition board (Axon Instruments) and subsequently converted and analyzed in Spike2 (version 4; Cambridge Electronic Design, Cambridge, UK) using programs written in the Spike2 script language. Analyzed data were plotted, and statistical tests were performed in Statview (version 5; SAS Institute, Cary, NC). Final figure composition was done in Adobe Illustrator 10 (Adobe Systems, Mountain View, CA). Data are presented here as plots of the cycle frequency (the inverse of the cycle period). An inverse operation, however, changes the variance of the sample; therefore, paired $t$ tests for statistical significance were performed on the cycle periods. For quantification, cycle frequencies were first plotted over time. Time stretches of several minutes in which the range of values did not change visibly were assumed to represent the steady state and used to determine the means. Paired and unpaired $t$ tests were used to establish statistical significance. In all cases, statistical significance was assumed at $p<0.05$. Statistical significance is indicated in bar plots by asterisks $\left({ }^{*} p<0.05 ;{ }^{* *} p<0.01\right)$. All histograms presented here represent the mean \pm SE unless stated otherwise.

\section{Results}

Anatomy of the stn-son junction: possible locus for modulation of descending axonal projections

Previous immunocytochemical studies have described peptide and amine-containing processes and varicosities in the area of the 
$\boldsymbol{A}$
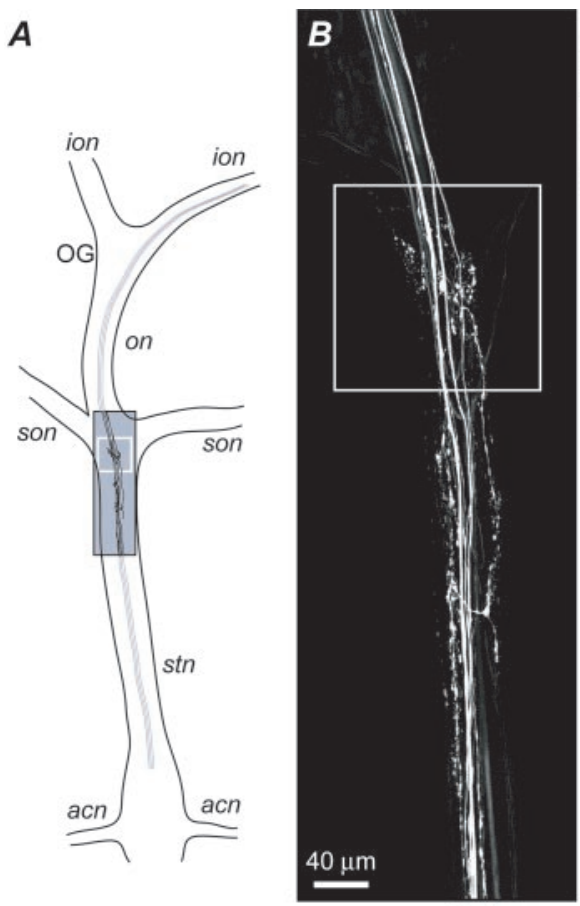

neurobiotin

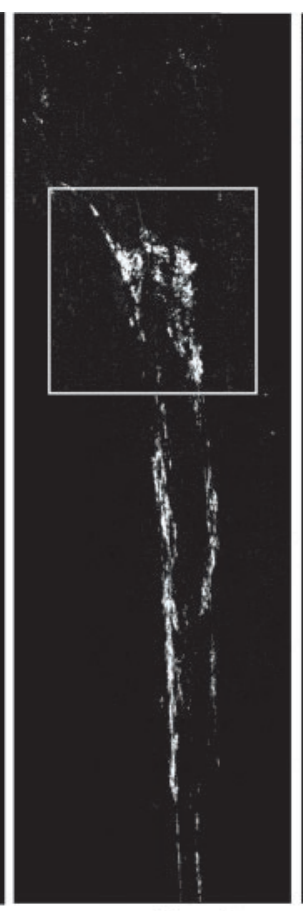

synaptotagmin
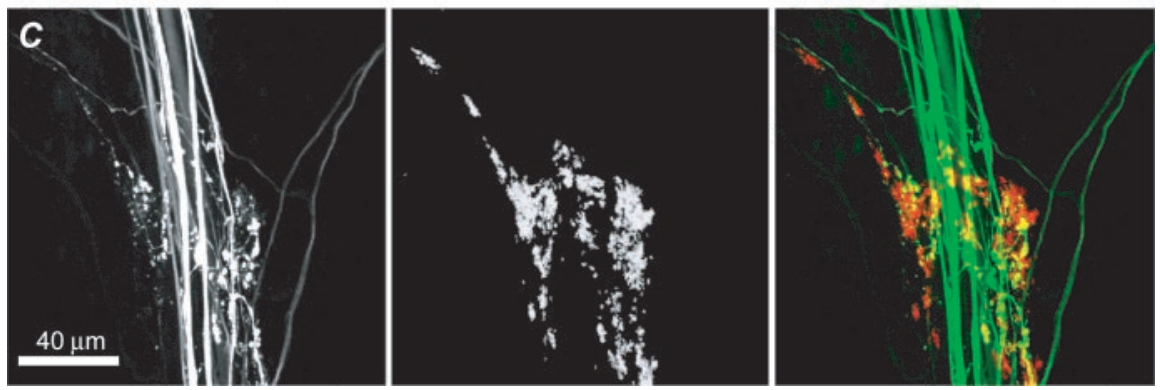

Figure 2. Synaptic vesicle staining surrounds ion axon collaterals at the level of the stn-son junction. Axons were filled with neurobiotin, which was then visualized by streptavidin coupled to $C y 5(B, C$, green), and synaptic vesicle-containing structures were revealed by anti-synaptotagmin staining visualized with anti-rabbit lgG coupled to AlexaFluor 488 ( $B, C$, red). $A$, Schematic of the preparation showing the origin and the trajectory of the neurobiotin-filled axons. The black and white boxes represent the location of the pictures presented in $B$ and C. B, Low magnification of the neurobiotin staining (left panel, green) and the synaptotagmin staining (middle panel, red) at the level of the stn-son junction. $C$, High-magnification pictures of the region surrounded in $B$. Note that the synaptotagmin staining is specifically located around the fine axon processes and not around the main axon branches.

stn-son junction (Fig. 2A) (Marder et al., 1986, 1987; Kilman et al., 1999; Skiebe, 1999; Skiebe et al., 1999), suggesting that this region is a potential site for synaptic and/or modulatory interactions among fibers traveling in the $s t n$. We labeled the fibers projecting from the ion to the stn by backfilling the ion fibers with neurobiotin and then immunostaining these preparations for synaptotagmin (Fig. $2 B$ ). The neurobiotin-filled ion fibers travel through the stn-son junction as well as make fine branches with varicosities in this region. Diffuse areas of synaptotagmin staining are colocalized with or in very close apposition to some of the filled fibers. The higher-magnification views of the central area of this region (Fig. 2C) confirm the intermingling of the ionprojecting fibers with synaptic vesicle-containing structures. This experiment was done four times, resulting in five to seven dyefilled axons in the stn in each experiment.

The confocal images in Figure 2 suggest that synaptic contacts might occur between fibers traveling in the $s t n$. The presence of anatomical synapses at the $s t n-s o n$ junction was confirmed by
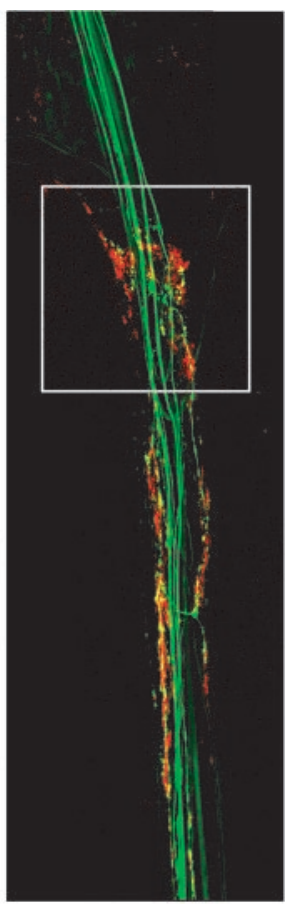

merge electron microscopy (Fig. 3). The micrographs in Figure 3 were sections taken parallel to the long axis of the stn at the level of the $s t n-s o n$ junction. Figure $3, A$ and $B$, shows low- and high-magnification views of a superficial section from this region. At high magnification these images show synapses similar to those described in the STG, with small clear vesicles and densecore vesicles (Kilman and Marder, 1996), large presynaptic sites, and rather small postsynaptic elements. Moreover, presynaptic terminals that make contact with several postsynaptic elements are seen (Fig. $3 B$ ). The location of the synapses and the size of the postsynaptic elements suggest that these are mainly axon collaterals and varicosities. The high density of densecore vesicles in most of the terminals suggests that peptides and/or amines are released onto the postsynaptic elements.

These data are consistent with a number of previous studies in both $C$. borealis and other species that reported immunostained punctate structures for amines and peptides in the stn-son junction (Marder et al., 1986, 1987; Callaway et al., 1987; Mortin and Marder, 1991; Kilman et al., 1999; Skiebe, 1999; Skiebe et al., 1999). These punctate structures are found within the nerve where most of the modulatory axons coming from the CoGs and the OG are located. They are distinct from larger neurohemal structures that lie at the nerve-sheath interface or within the sheath. In other species this region of punctate staining within the nerve has also been shown previously to have synaptic contacts (Skiebe and Ganeshina, 2000; Skiebe and Wollenschlager, 2002) that are labeled with synaptotagmin.

The presence of synaptic neuropil at the stn-son junction suggested that the postsynaptic targets, in this case axons in the $s t n$, might display receptors to neuromodulatory substances. In a preliminary study, Kilman (1998) applied a number of substances to this region and found that octopamine applied to the stn-son junction influenced the motor patterns of the STG. In the remainder of this paper we characterize these effects and show that octopamine activates one of the known identified modulatory projection neurons, MCN5, at this site.

The effects of octopamine application to the stn-son junction on the pyloric rhythm

The pyloric rhythm consists of a triphasic sequence of bursting activity of the two pyloric dilator (PD) neurons, the single lateral pyloric (LP) neuron, and the five pyloric (PY) neurons that can be recorded on the lateral ventricular nerve ( $l v n)$ (Hooper et al., 1986; Weimann et al., 1991). We routinely measured the cycle period of the pyloric rhythm from the PD neuron activity recorded on the pyloric dilator nerve $(p d n)$.

We did a series of experiments in which we built a large petro- 
leum jelly well at the stn-son junction (Fig. 1) that allowed us to continuously superfuse the $s t n-s o n$ junction separately from the superfusion of the rest of the preparation while extracellularly recording the activity of the pyloric network. The effects of applying $10^{-4} \mathrm{M}$ octopamine to the stn-son junction can be seen in Figure $4, A$ and $B$. This example shows clearly that octopamine increased the frequency of the pyloric rhythm. In pooled data from 13 experiments, the mean cycle frequency of the pyloric rhythm was $1.1 \pm 0.05 \mathrm{~Hz}(n=13$ experiments) in control saline (Fig. 4C). When octopamine $\left(10^{-4} \mathrm{M}\right)$ was applied to the stn-son junction, it induced a significant and reversible increase in the cycle frequency $(1.31 \pm 0.05 \mathrm{~Hz}$ in octopamine; $p<0.01 ; n=13)$.

The octopamine effect could be the consequence of one of the following: (1) octopamine directly acting on an STG neuron that projects up to the CoGs (Nagy et al., 1994), (2) octopamine acting on descending modulatory axons, or (3) octopamine acting on ascending axons projecting to the CoGs or OG that in turn activate descending modulatory projection neurons. To discriminate among these possibilities, we took advantage of the fact that most of the modulatory projection neurons are located in the CoGs (Coleman et al., 1992). Therefore, we cut the ions and the sons close to their connection to the CoGs to prevent any indirect activation of modulatory projection neurons. Figure $4 D$ shows an example of the pyloric rhythm in control saline and after octopamine was added to the stn-son junction under these conditions. Figure $4 E$ again shows the time course and evolution of the octopamine-induced frequency increase. Removing the CoGs $(n=17)$ reduced the baseline frequency of the pyloric rhythm to $0.95 \pm 0.04 \mathrm{~Hz}$ without changing the peak frequency obtained when octopamine was applied to the stn-son junction $(1.3 \pm 0.05 \mathrm{~Hz}$ in the presence of octopamine; $p<0.01$ ) (Fig. $4 C$ ). Octopamine $\left(10^{-6} \mathrm{M}\right)$ increased the frequency from $0.94 \pm 0.07 \mathrm{~Hz}$ in control saline to $1.18 \pm 0.09 \mathrm{~Hz} ; p<0.05 ; n=3)$.

In addition to producing changes in frequency, many neuromodulators also alter the phase relationships or the relative time of firing of the pyloric network neurons (Marder and Weimann, 1992; Weimann et al., 1997; Nusbaum et al., 2001; Nusbaum and Beenhakker, 2002). Figure $4 F$ shows the phase relationships of the PD, LP, and PY neurons in control saline and after octopamine was applied to the stn-son junction. Note that the duty cycle of the PD neurons was slightly increased and the LP neuron terminated its burst slightly later, but these changes were relatively modest.

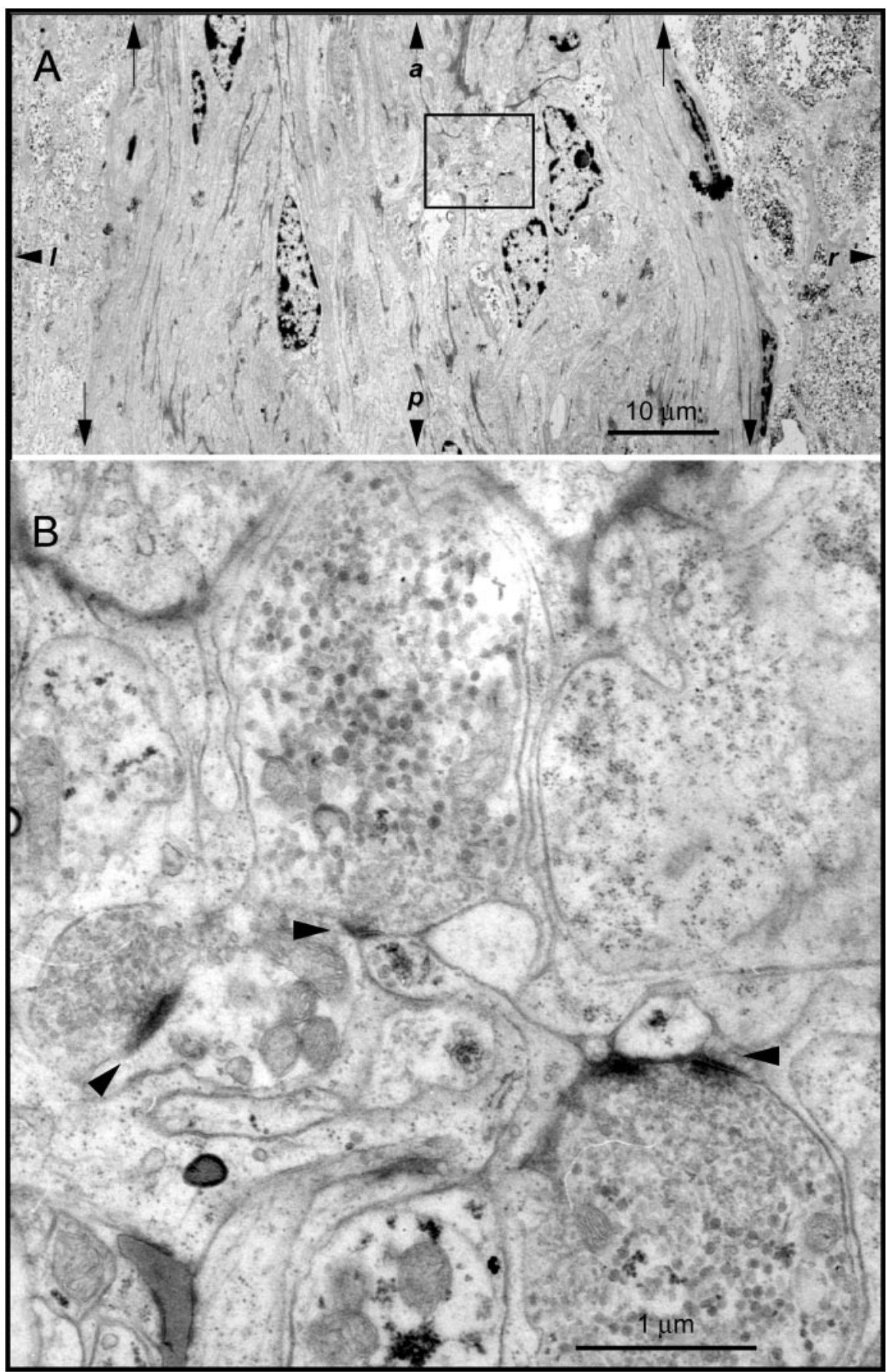

Figure 3. Synapses are present in the core of the nerve at the level of the stn-son junction. Electron micrographs of the stn taken parallel to the axis of the nerve at the level of the stn-son junction $(A, B)$. $A$, Low-magnification picture of the stn-son junction. The limits between the nerve and the sheath are indicated by vertical black arrows, and the orientation of the picture is indicated by the arrowheads ( $a$, anterior; $p$, posterior; $I$, left; $r$, right). Large diameter neurites with an anterior-posterior orientation can be observed, as well as fine processes forming synaptic contacts (black box). B, High magnification of the region indicated by the black box in $A$. Synaptic contacts (black arrowheads) are formed by large presynaptic elements that contain both dense-core vesicles and small clear vesicles on small postsynaptic elements.

These experiments demonstrate that the octopamine effect does not rely on the indirect activation of modulatory neurons in the CoGs and that the amplitude of the octopamine effect is dependent on the baseline frequency of the pyloric rhythm, which in turn depends on the presence of the descending modulatory inputs. The percentage of increase in the pyloric rhythm frequency was significantly larger when the connections to the 
A

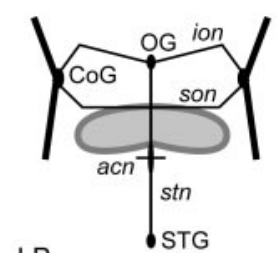

PD|PY Control

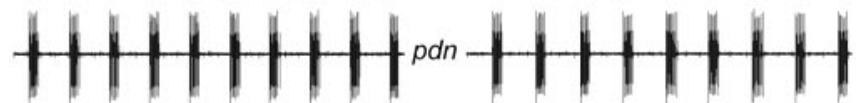

$10^{-4} \mathrm{M} \mathrm{OA}$ $\mathrm{HHHHH}$ od $\mathrm{HHHHH}$
D

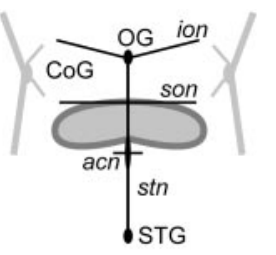

Control

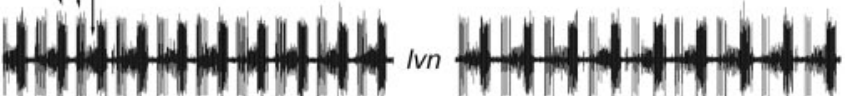

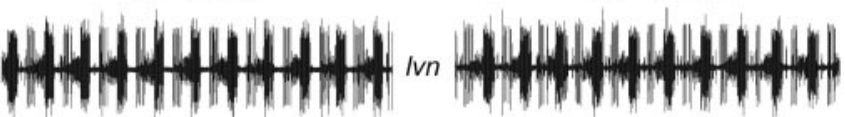
Hillilllilim

B

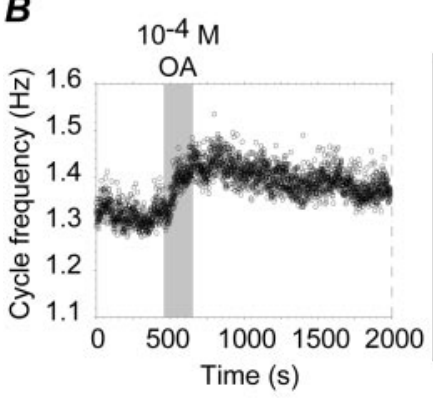

C

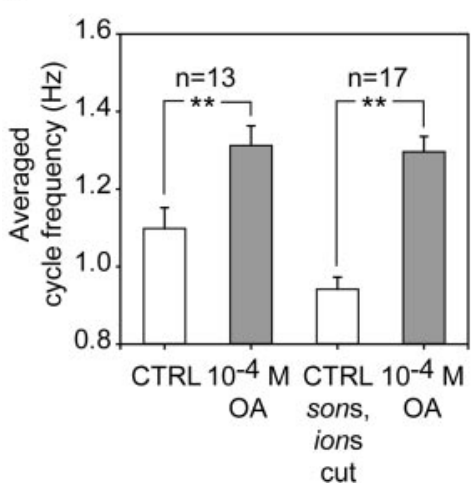

E

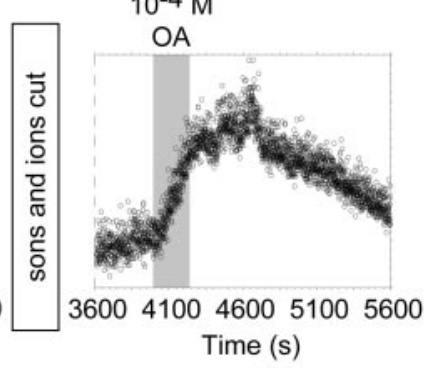

$\boldsymbol{F}$

Control $\square 10^{-4} \mathrm{M} \mathrm{OA}$

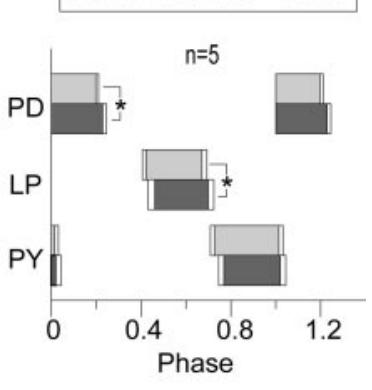

Figure 4. Octopamine actions on the stn-son junction. Octopamine $\left(10^{-4} \mathrm{M}\right)$ was applied for $5 \mathrm{~min}$ in a petroleum jelly well covering the stn-son junction ( $A$ and $D$ schematics; gray "bowtie" shape). $A$, The effects of octopamine applied to the stn-son junction. The traces are extracellular recordings from the /vn and $p d n$ showing the activity of the LP, PY, and PD neurons in control (top) and octopamine (bottom). $B$, Plot of the instantaneous pyloric frequency before, during, and after the octopamine application shown in $A$. C, Histograms of the mean cycle frequency before and after octopamine application in data pooled from multiple experiments. $D$, Same experiment as $A$ after removing the CoGs influence by cutting the ions and the sons. $E$, Measurements of the instantaneous cycle frequency over time show clearly that cutting the ions and sons changes only the baseline cycle frequency without changing the peak frequency reached in octopamine. $F$, Phase relationships of the $P D, L P$, and $P Y$ neurons before and during octopamine application. The main bars (light and dark gray) represent the mean duty cycle for each cell studied. The white error bars represent the SE of the duty cycle when placed to the right of the main bar and the SE of the $0 \mathrm{~N}$ phase when placed to the left of the main bar.

A

Control

ion (1)

ion (2)

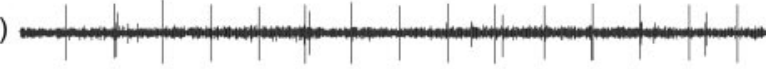

ion (3)

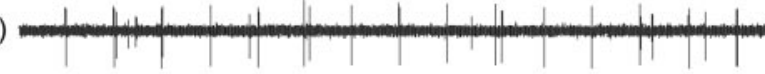

on (4)

$\operatorname{stn}(5)$
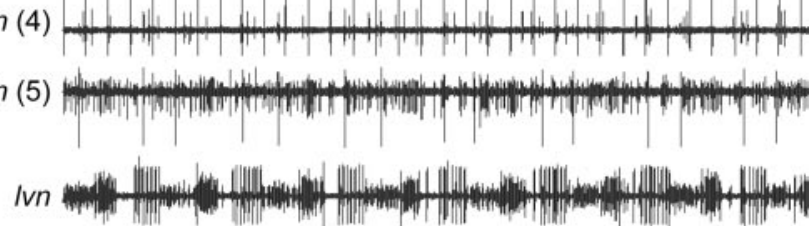

pdn

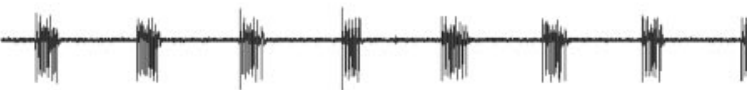

$10^{-4} \mathrm{M} \mathrm{OA}$

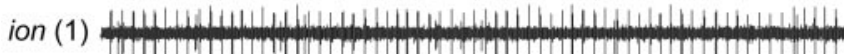

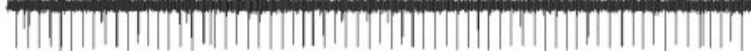

ion (2)

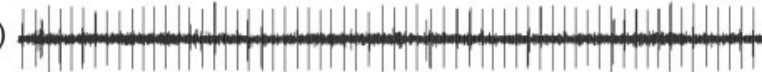

ion (3)

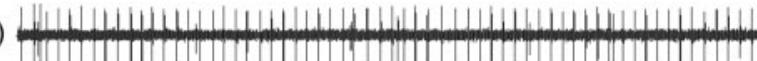

on (4)

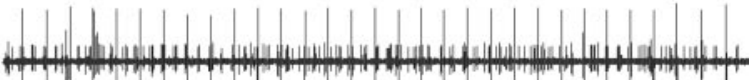

$\operatorname{stn}(5)$

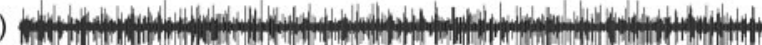

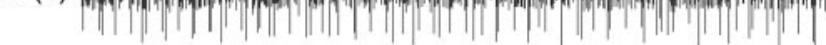
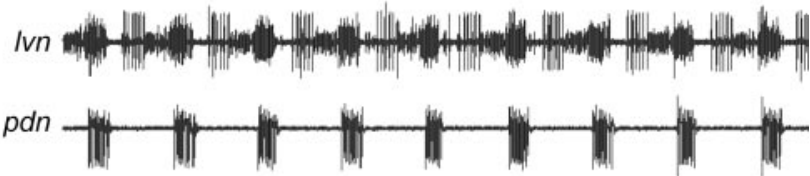

B

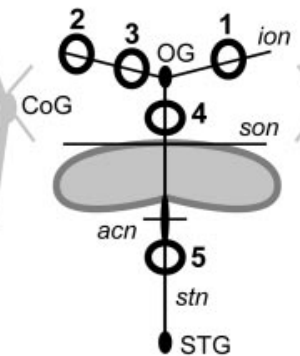

C
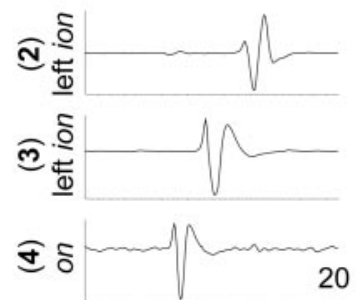

ลี

$$
\begin{array}{cccc}
-20 & -10 & 0 & 10 \\
& \text { Time }(\mathrm{ms})
\end{array}
$$

Figure 5. Analysis of spike conduction for the activated unit. Octopamine $\left(10^{-4} \mathrm{M}\right)$ was applied for $5 \mathrm{~min}$ to the stn-son junction. The sons and ions were cut close to the CoGs. $A$, Extracellular recordings showing that the activated unit is seen on the ions and on the on as a small spike but is difficult to distinguish in the stn recording because of activity of other units. $B$, Schematic of the preparation showing the recording sites. $C$, Average traces triggered on the unit recorded on the left ion (recording site 2) show the spike conduction along the ion, the on, and down the stn. The delays measured for the different recording sites suggest that the spike initiation site is located at an approximately equal distance from the stn and the on recording sites. It also demonstrates that the spikes are conducted down the stn. 


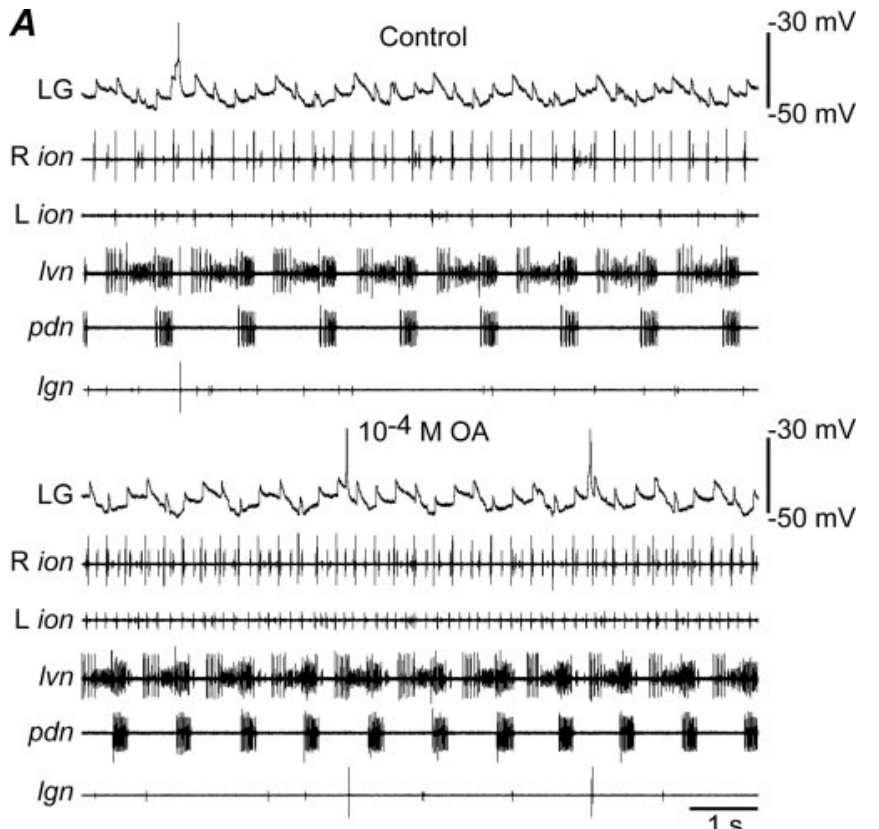

B

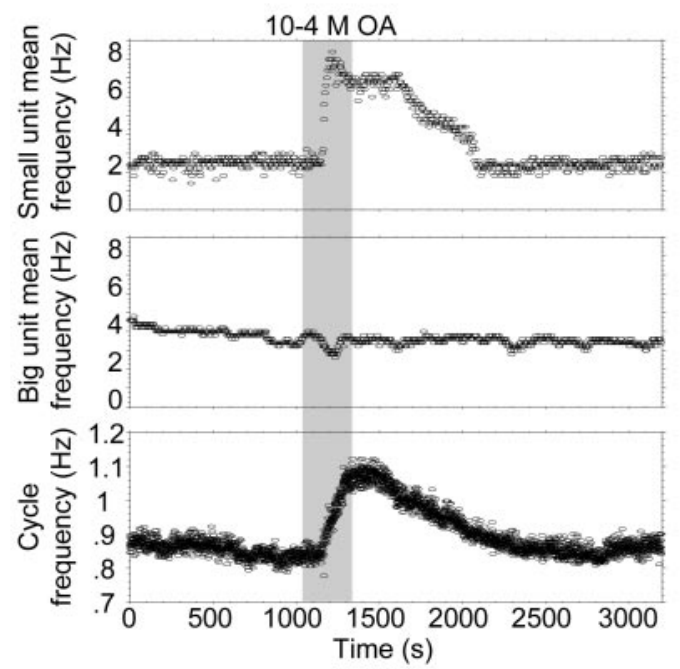

D

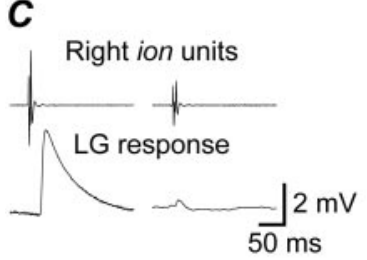

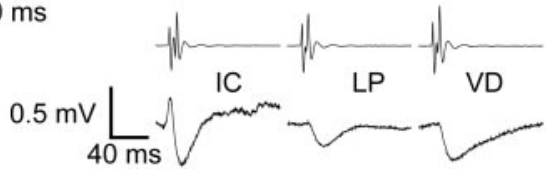

Figure 6. Identification of the axon activated by octopamine. Octopamine $\left(10^{-4} \mathrm{M}\right)$ was applied for $5 \mathrm{~min}$ to the stn-son junction. The sons and ions were cut close to the CoGs. Data presented in $A-C$ were from the same experiment. $A$, Intracellular recording from the $L G$ neuron and extracellular recordings from the ions, Ivn, $p d n$, and lateral gastric nerve (Ign) before (control) and during octopamine application. Octopamine application activated a small unit in both ions. The big unit recorded on the right ion was not affected by octopamine application. № obvious change in $L G$ neuron activity was observed after octopamine application. $B$, Plots of the mean frequency of the ion units over time show that the small unit was activated by octopamine, whereas the big unit recorded on the right ion was unaffected by octopamine application. The activation of the ion unit occurred before the increase in the frequency of the pyloric rhythm and returned to baseline before the recovery of the pyloric rhythm frequency. C, Spike-triggered average of the $L G$ neuron recording shows that the big unit on the right ion is time-locked with

CoGs were cut $(39.2 \pm 5.1$ vs $21.1 \pm 4.5 \%$; $p<0.05)$. Thus, these experiments suggest that octopamine acts on projection neurons descending to the STG or directly on the neuropil of an STG neuron.

Inferior esophageal nerve axon activation by octopamine To determine whether octopamine acts directly on modulatory projection neurons, we performed ion and son recordings while applying octopamine at the $s t n-s o n$ junction. No significant change in the pattern of activity was seen in the son recordings during octopamine application (data not shown); however, octopamine systematically increased the activity of one unit in each ion (Fig. 5). This unit was either silent or weakly active in control saline. Regular tonic firing was elicited in response to octopamine. Spike frequency increased from $1.4 \pm 0.3 \mathrm{~Hz}$ in control saline to $10.1 \pm 0.4 \mathrm{~Hz}$ in $10^{-4} \mathrm{M}$ octopamine $(p<0.01 ; n=22) ; 10^{-6} \mathrm{M}$ octopamine increased the spike frequency from $1.5 \pm 0.6$ to $7.06 \pm 0.4 \mathrm{~Hz}(p<0.01 ; n=4)$. The peak frequency in $10^{-6} \mathrm{M}$ octopamine was not statistically different from that in $10^{-4} \mathrm{M}$ octopamine $(p>0.05 ; n=4)$.

These experiments suggest that octopamine acts directly on a pair of neurons with axons that are found in the ions and at the stn-son junction. For this pair of axons to be involved in the modulation of the pyloric rhythm observed when octopamine is applied on the stn-son junction, however, the spikes generated at the stn-son junction must propagate down the stn and eventually release transmitter onto STG cells. These units are indeed found in $s t n$ recordings, although their small size required averaging to make them visible (Fig. 5). Triggering the averaging on one of the ion recordings revealed that the spikes were initiated at the $s t n-$ son junction when octopamine was applied there and then traveled down the stn and up the on and the ions (Fig. 5C).

\section{Identification of the axon activated by octopamine}

Only two neurons located in the CoGs project through the ion and then to the stn and the STG (Coleman et al., 1992). One of these neurons is MCN1 (Coleman and Nusbaum, 1994) and the other is MCN5 (Norris et al., 1996). Several criteria discriminate between these two neurons: (1) the size of the action potentials on the ion recording, (2) their neuronal targets in the STG and their synaptic potentials in STG neurons, and (3) their relation to esophageal motor neuron activity. MCN5 spikes are approximately one-half the amplitude of $\mathrm{MCN} 1$ spikes in ion recordings (Norris et al., 1996). In our experiments when the ions and sons were cut, the ion unit activated by octopamine was always a small unit, whereas the large unit was unaffected by octopamine application (Fig. 6A). In six experiments in which a large unit was recorded in the ion, no effect of octopamine on the activity of this unit was seen, whereas a change in the small unit activity was observed in all experiments involving ion recordings $(n=22)$. Thus, the ion recordings suggested that the big unit insensitive to octopamine is MCN1 and MCN5 is the small unit activated by octopamine.

\section{$\leftarrow$}

an EPSP in the LG neuron. The small unit does not evoke the large EPSP in the $L G$ neuron. Baseline membrane potential was $-46 \mathrm{mV}$ for both traces. D, Synaptic events time-locked to the activity of the small ion unit recorded in three different preparations (PD and VD neuron recordings were from the same experiment). Top, Superposition of EPSPs in the PD recordings time-locked to the ion small unit spike ( 7 traces). Bottom, Spike-triggered averaging shows that the ion small unit is time-locked with IPSPs in the IC, LP, and VD neurons. The events recorded in IC were biphasic, with a first brief depolarization and a longer hyperpolarization. Baseline membrane potentials were $-45,-63$, and $-61 \mathrm{mV}$ for $\mathrm{IC}, \mathrm{LP}$, and VD neuron traces, respectively. 
To verify this, we took advantage of the known postsynaptic actions of MCN1 and MCN5 (Norris et al., 1996). MCN1 evokes EPSPs in the lateral gastric (LG) neuron and receives IPSPs from this target neuron (Nusbaum et al., 1992), whereas MCN5 evokes EPSPs in the anterior burster, PD, and lateral posterior gastric (LPG) neurons and IPSPs in the inferior cardiac (IC), LP, and ventricular dilator (VD) neurons (Norris et al., 1996). We identified the large unit recorded on the ion as MCN1 because it evoked large EPSPs in the LG neuron, whereas the small unit did not evoke a synaptic response in the LG neuron $(n=2)$ (Fig. $6 C$ ). Conversely, we identified the small unit activated by octopamine as MCN5 because it evoked EPSPs in the PD neurons and IPSPs in the IC, LP, and VD neurons (Fig. 6D). This identification was further corroborated by the fact that as previously reported (Norris et al., 1996), the synaptic potentials recorded in the IC neuron were biphasic, with a brief depolarization preceding a longer hyperpolarization, whereas those recorded in LP and VD were only hyperpolarizing (Fig. $6 D$ ). In summary, these data demonstrate that MCN5 is the ion unit affected by octopamine and that MCN1 is unaffected by octopamine under these conditions.

To further characterize the effects of octopamine on MCN5, we recorded from its soma intracellularly and applied octopamine. As described previously (Norris et al., 1996), with the sons intact, the MCN5 intracellular recordings in control saline (Fig. 7A) show pyloric-timed inhibition (arrowheads) and single 15 $\mathrm{mV}$ action potentials. In response to octopamine, the spike frequency in MCN5 increased strongly (see also the increased activity of the small unit on the ion). The spikes seen in the trough of the inhibition were antidromic and peripherally initiated and propagated into the soma. When we cut the sons (Fig. $7 B$ ), the pyloric-timed inhibition was lost (Norris et al., 1996) but excitation from esophageal units was revealed (arrowheads) as expected for MCN5 (Norris et al., 1996). Under these conditions, even lower concentrations of octopamine produced dramatic increases in MCN5 firing (Fig. 7B).

We took advantage of the intracellular recordings from MCN5 to depolarize MCN5 to make it fire at frequencies similar to those evoked by octopamine. When the stimulated MCN5 fired at a mean frequency of $15 \mathrm{~Hz}$ for $30 \mathrm{sec}$, the pyloric frequency increased from $0.97 \pm 0.13$ to $1.11 \pm 0.1 \mathrm{~Hz}(p=$ $0.05 ; n=3$ experiments). This suggests that MCN5 is responsible for at least part of the increase in frequency of the pyloric rhythm in response to octopamine application to the $s t n-s o n$ junction.

Thus far we have shown that octopamine can influence the pyloric rhythm by activating the axons of descending modulatory neurons. In the next set of experiments we ask whether octopamine also acts directly on neuronal targets within the STG itself.

\section{Effects of bath-applied octopamine after blockade of the modulatory inputs}

One way to analyze the direct effects of octopamine on the STG network is to block the activity of modulatory inputs by applying a TTX-sucrose solution to the $\sin$ (Russell, 1976). In the absence of activity in the descending modulatory inputs, the pyloric rhythm slows or stops, facilitating the observation of weak excitatory modulatory effects. Octopamine application to the stnblocked preparations reactivated a full pyloric rhythm (Fig. $8 A, B)$. In data pooled from seven experiments, the mean frequency of the pyloric rhythm was $0.31 \pm 0.07 \mathrm{~Hz}$ in control saline and $0.91 \pm 0.05 \mathrm{~Hz}$ in response to octopamine application to the STG $(p<0.01 ; n=7)$ (Fig. $8 C$ ). Phase plots for the pyloric rhythm in control saline and octopamine (Fig. $8 D$ ) (to make
A
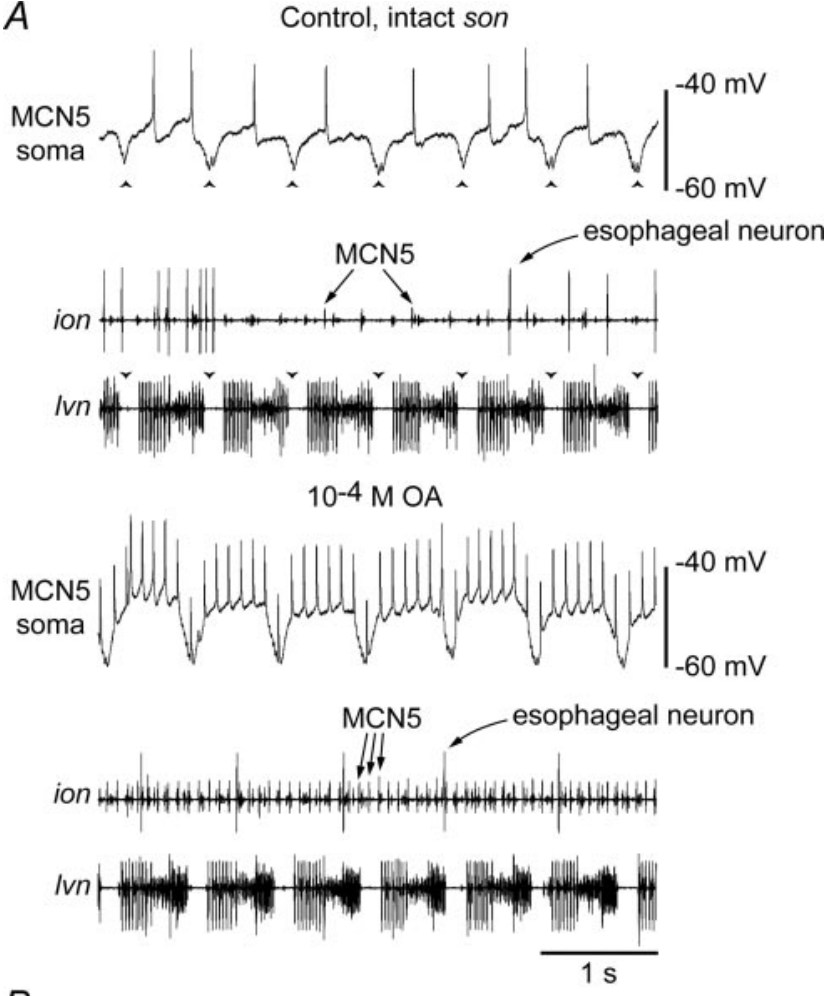

$B$

Control, son cut
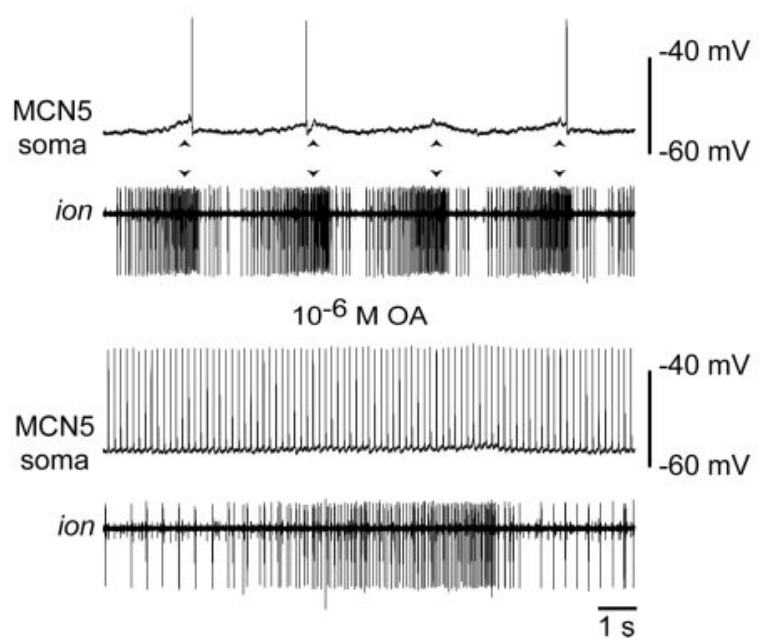

Figure 7. Intracellular recordings of MCN5 neurons. Octopamine was applied to the whole STNS for 5 min at a concentration of $10^{-4} \mathrm{M}(A)$ or $10^{-6} \mathrm{M}(B)$. A, Intracellular recording of the MCN5 in an intact preparation showing the pyloric-timed inhibition (arrowheads in top and bottom traces) and the extracellular spikes recorded on the ion (arrows) corresponding to the intracellularly recorded spikes. Application of $10^{-4} \mathrm{M}$ octopamine on this preparation (A, right panel) induced an increase in MCN5 firing frequency. Antidromic spikes (during pyloric-timed inhibition) and orthodromic spikes (top of the oscillation) can be observed on the intracellular recording during octopamine application (top trace). B, MCN5 intracellular recording and ion extracellular recording in a preparation in which the sons have been cut to prevent pyloric-timed inhibition showing esophageal-timed excitation of MCN5 (arrowheads). In control condition (left panel), MCN5 fires a single action potential on top of the esophageal-timed excitation. During $10^{-6} \mathrm{M}$ octopamine application (right panel), MCN5 fires tonically independently of the esophageal-timed oscillations of the membrane potential.

these plots, only those experiments in which the rhythm was active before octopamine application were used in the controls) illustrate that the duty cycle of the PD neurons was increased slightly and the LP and PY neurons fired later in octopamine than in the control. 
A

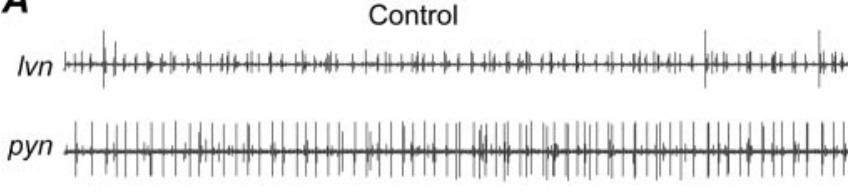

$p d n$

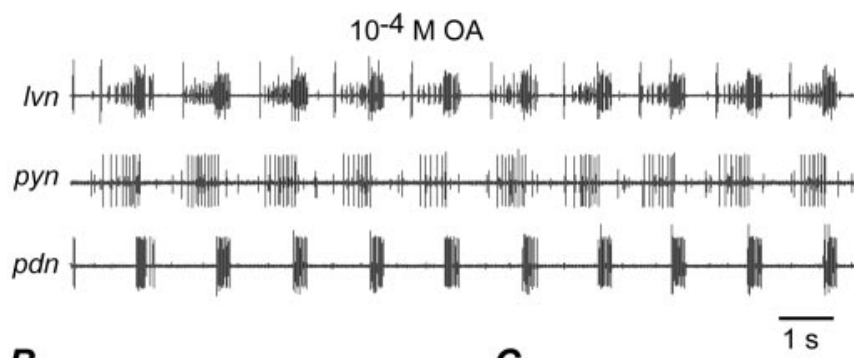

B

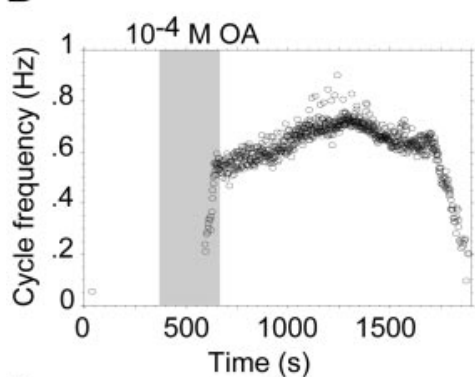

C

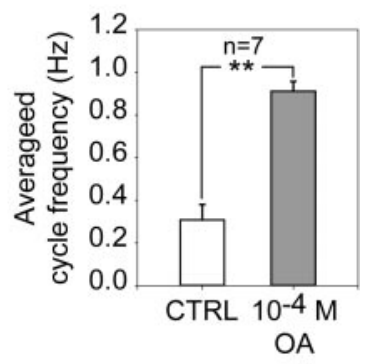

$\boldsymbol{D}$

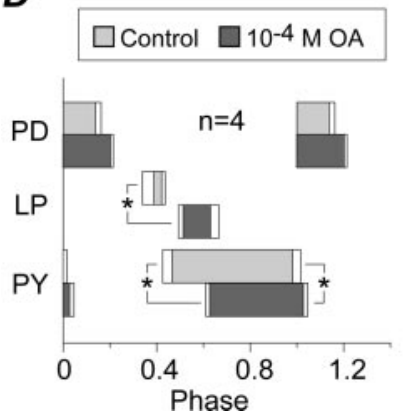

Figure 8. Octopamine actions on the STG. Octopamine $\left(10^{-4} \mathrm{M}\right)$ was bath-applied to the STG after modulatory inputs from the CoGs and the $0 G$ were removed by blocking impulse activity in the stn with TTX-sucrose. $A$, In control saline the PY neurons fired tonically, the LP neuron showed a very low level of activity, and the PD neurons were silent. After the $5 \mathrm{~min}$ application of octopamine, the pyloric rhythm resumed. $B$, Plot of the cycle frequency over time shows that octopamine induced a slow but stable pyloric rhythm for $>20$ min after the end of the application. C, Octopamine induced a significant increase in the averaged cycle frequency in seven preparations ( $p<0.01$; paired $t$ test). D, Phase relationships ( \pm SEM) among PD, LP, and PY cells before and during octopamine application. Light bars are control; dark bars are octopamine application.

\section{Effects of bath-applied octopamine on the intact stomatogastric nervous system}

We then studied the effect of applying octopamine to the entire STNS (Fig. 9). The raw traces in Figure $9 A$ and the time course data (Fig. 9B) show a dramatic increase in frequency. Pooled data from 18 preparations (Fig. 9C) showed increases of pyloric rhythm frequency (from $1.1 \pm 0.05 \mathrm{~Hz}$ in control saline to $1.57 \pm$ $0.06 \mathrm{~Hz}$ in octopamine; $p<0.01 ; n=18 ; 10^{-6} \mathrm{M}$ octopamine increased the cycle frequency from $1.21 \pm 0.07$ to $1.36 \pm 0.08 \mathrm{~Hz}$ $(p<0.05 ; n=3)$. The phase plots in Figure 9D demonstrate that the PD and PY neuron duty cycles increased and the LP neuron duty cycle decreased in octopamine.

Figure 10 summarizes the effects of octopamine application as a function of the initial baseline of the pyloric rhythm under all of the different conditions described here. First, regardless of initial pyloric frequency, applications to the entire STNS were more effective than applications to the stn-son junction, which is consistent with the previous observation that the mean peak frequencies obtained for these two kinds of applications are different, whereas the baseline frequencies are not (Figs. 4C, 9C). Second, the excitatory actions of octopamine were larger when the initial frequency was low, regardless of where the octopamine application was made. The greatest percentage increase in pyloric frequency caused by octopamine application was obtained when the baseline frequency was at its lowest (Fig. 10B).

\section{Discussion}

Most rhythmic behaviors are produced by central pattern generating networks that are activated, inhibited, and otherwise modulated by descending modulatory projections that reconfigure the central pattern generating networks to generate behaviorally relevant motor patterns (Marder and Calabrese, 1996). Here we demonstrate that the axon of one of the descending modulatory projection neurons in the stomatogastric nervous system is itself modulated by octopamine. This modulation takes place at a specialized location at which there are synapses onto and from axonal projections of numerous neurons. This site is also the place at which bilaterally symmetrical ganglia and neurons join into a single midline nerve.

\section{Interactions between parallel modulatory pathways}

The STG is the direct target of 20-25 pairs of descending modulatory neurons (Coleman et al., 1992; Blitz and Nusbaum, 1997; Blitz et al., 1999), including the MCN5 neurons (Norris et al., 1996), the neurons that are sensitive to octopamine. The presence of synaptic structures at the stn-son junction suggests that octopamine itself could be released by another modulatory projection neuron coming from the OG or the CoGs. This would not be the first case of interaction between modulatory pathways. Blitz and Nusbaum $(1997,1999)$ demonstrated that the modulatory proctolin neuron (MPN) inhibits the gastric rhythm by inhibiting a parallel modulatory pathway composed of MCN1 and the commissural projection neuron 2 (CPN2) (Blitz and Nusbaum, 1997, 1999). Although the excitation of the pyloric rhythm by MPN occurs in the STG as a consequence of proctolin release, the inhibition of MCN1 and CPN2 is mediated by GABA and occurs in the CoGs, where the cell bodies of these three neurons are located (Blitz and Nusbaum, 1999). Therefore, MPN-mediated inhibition of MCN1 and CPN2 enables the production of a pure "pyloric" rhythm, in the absence of the gastric rhythm ordinarily activated by MCN1 and CPN2. Analogously, a putative octopaminergic modulatory neuron that activates MCN5 at the level of the stn-son junction could circumvent the pyloric and esophageal inhibition that this neuron receives in the CoG and therefore amplify the effect of MCN5 on the pyloric and gastric networks.

\section{Comparison of the effects of octopamine and MCN5 stimulation}

We noticed important differences between the effects of octopamine application to the stn-son junction and MCN5 stimulation. Although octopamine application induced a $20-40 \%$ increase in the pyloric rhythm frequency, MCN5 stimulation at a frequency close to that evoked by octopamine induced only a $10-20 \%$ increase in the pyloric rhythm frequency. This difference probably reflects the respective involvement of one (intracellular stimulation) or two (octopamine application) MCN5 fi- 
A
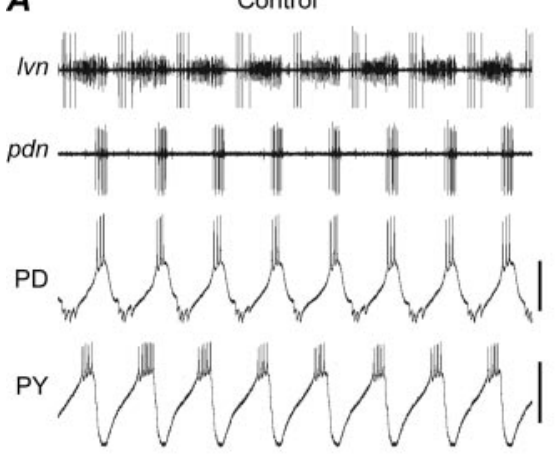

$10^{-4} \mathrm{M} \mathrm{OA}$
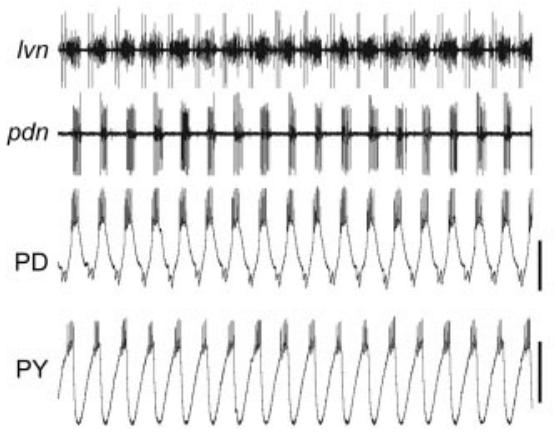

Wash

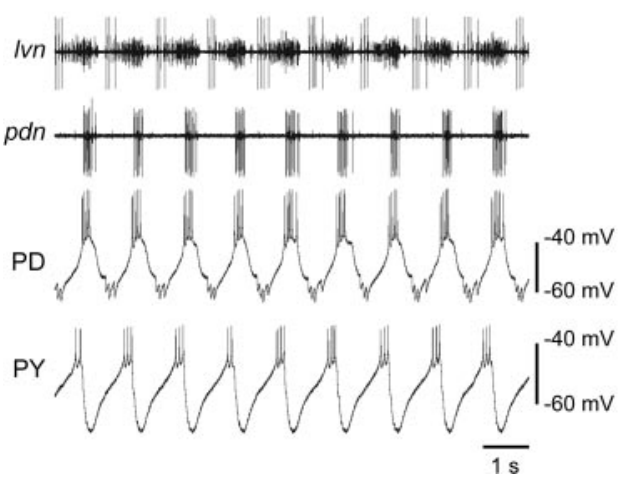

Figure 9. Octopamine actions on the STNS. Octopamine $\left(10^{-4} \mathrm{M}\right)$ was bath-applied to the entire STNS. $A$, Extracellular recordings from the I $v n$ and $p d n$ and intracellular recordings from the PD and PY neurons before, during, and after 5 min octopamine application. 0ctopamine induced a reversible increase in the pyloric rhythm cycle frequency associated with strong depolarization of the PD membrane potential and slight depolarization of the PY membrane potential. $B$, Plot of the instantaneous pyloric frequency before, during, and after the octopamine application shown in A. C, Octopamine significantly increased the mean cycle frequency in 18 of 18 preparations ( $p<0.01$; paired $t$ test). D, Phase relationships ( $\pm S E M$ ) among PD, LP, and PY cells before and during octopamine application. Light bars are control; dark bars are octopamine application.

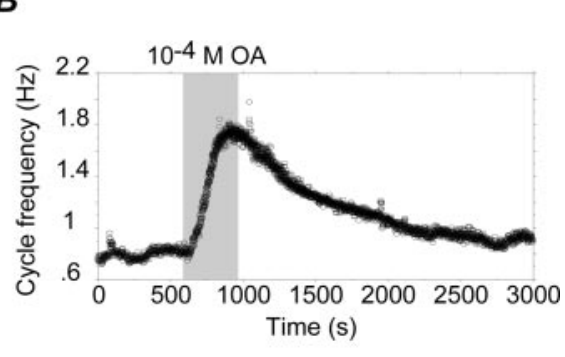

C

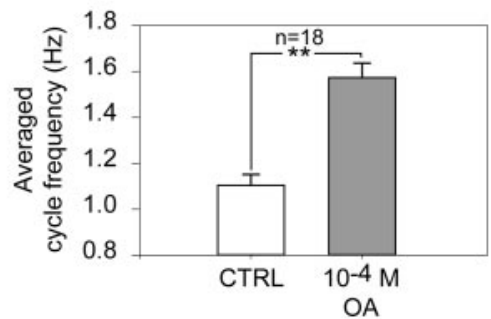

D

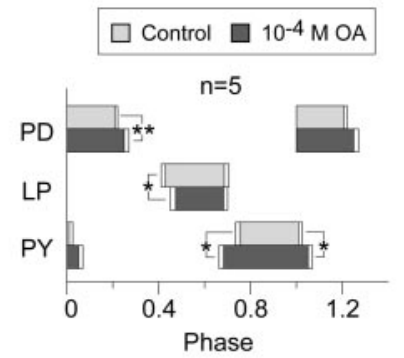

bers. Octopamine induced an increase in the pyloric frequency without significant changes in the phase relationships among the PD, LP, and PY neurons. In contrast, stimulation of a single MCN5 at $20-30 \mathrm{~Hz}$ decreased firing in the LP and PY neurons, resulting in strongly modified phase relationships among the pyloric network neurons (Norris et al., 1996). We observed a similar but weaker effect of MCN5 activity on the phase relationships of pyloric neurons when intracellularly stimulating a single MCN5 at $10-20 \mathrm{~Hz}$; however, in this case too, the involvement of one or two MCN5 fibers could account for the differences in phase relationships observed, especially if the two MCN5 fibers usually fire synchronously or if this functional coupling is promoted by octopamine. Therefore, the question of whether octopamine application to the stn-son junction activates other modulatory fibers remains open, although a significant part of the effect of this modulator can be explained by the activation of the two MCN5 fibers.

\section{Octopamine as a neuromodulator}

Octopamine is one of the most widely found and intensively studied neuromodulators in arthropods. Since its first characterization in lobsters (Barker et al., 1972), it has been implicated in a large variety of alterations in behavioral state (Harris-Warrick and Kravitz, 1984; Stevenson and Meuser, 1997; Roeder, 1999; Schulz and Robinson, 1999; Schulz et al., 2002; Kravitz and Huber, 2003). The effects of octopamine on the motor patterns of the STG have been described previously in the spiny lobster Panulirus interruptus (Flamm and Harris-Warrick, 1986a,b; Heinzel, 1988; Ayali and HarrisWarrick, 1999; Peck et al., 2001). There are some notable differences between the effects of octopamine on the pyloric rhythm in C. borealis reported here and those previously reported in $P$. interruptus. In $P$. interruptus, when the modulatory inputs were blocked, octopamine application activated the PD and LP neurons but had no effect on the PY neurons, which remained silent after octopamine application (Flamm and Harris-Warrick, 1986a). The resulting phase relationships were quite different from those we observed in C. borealis, with the PD duty cycle almost unchanged and an increased LP neuron duty cycle. In $P$. interruptus, when the modulatory inputs were left intact, octopamine slightly decreased the frequency of the pyloric rhythm because of the strong activation of the LP neuron (Peck et al., 2001). It is not clear whether the species differences in octopamine actions are caused by different cellular targets of octopamine. Moreover, considerably less is known about the identities and properties of the descending projection neurons in P. interruptus, and it is not known whether there is an MCN5 homolog in P. interruptus, and if so, whether octopamine activates it.

\section{Modulation occurs at multiple sites}

Our data demonstrate directly that octopamine can act at several sites to modulate the STG motor patterns. Minimally, the central pattern generating neurons in the STG are sensitive to octopamine, and octopamine acts directly on the descending modulatory neuron MCN5. The results of octopamine application to these two sites are not very different, and it is possible that the same network is coordinately modulated in a similar manner in two different ways. Previous work showed that octopamine is present and synthesized in the CoGs (Barker et al., 1979). Therefore, it is possible that a descending octopaminergic neuron with a soma in the CoG could release octopamine both at the stn-son junction and into the STG and that the resulting effect would closely resemble the effect of octopamine when applied to the intact STNS. 
$\boldsymbol{A}$

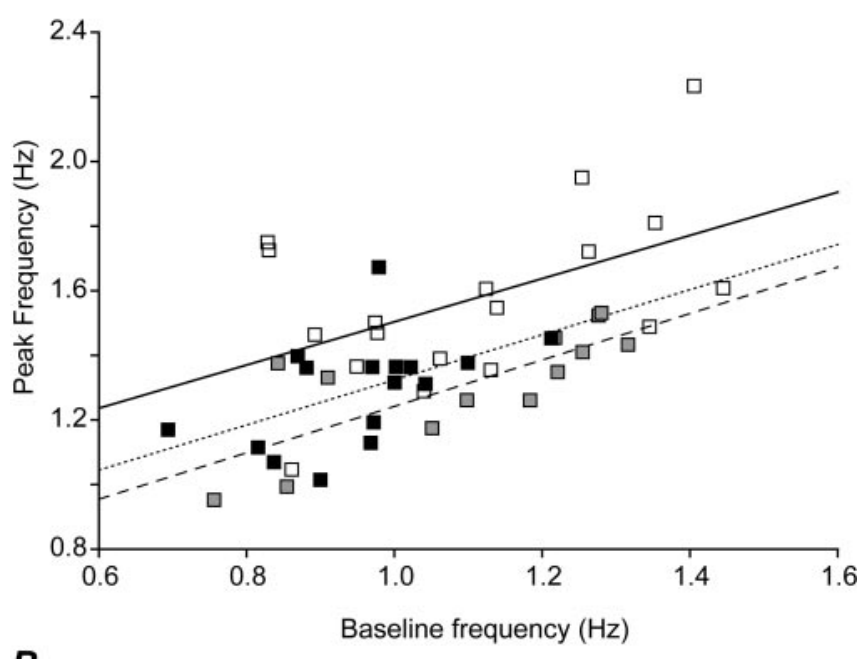

B

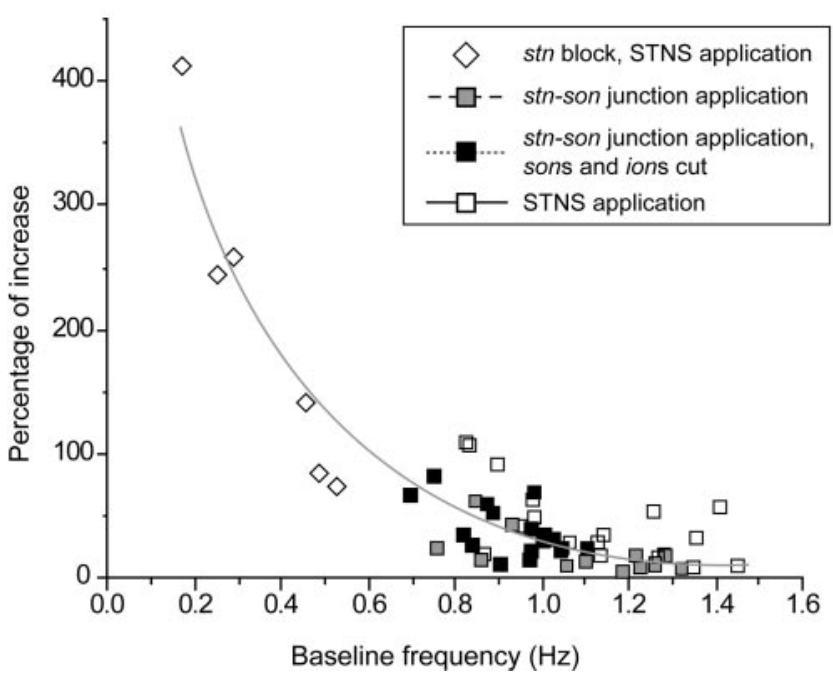

Figure 10. The effect of octopamine on peak frequency was dependent on the baseline frequency of the pyloric rhythm. $A$, Peak frequency during $10^{-4} \mathrm{M}$ octopamine treatment increased with increasing baseline frequency. The peak frequency of the pyloric rhythm was significantly higher $(p<0.001)$ during octopamine application to the STNS compared with application to the stn-son junction region regardless of baseline frequency. $B$, The magnitude of the effect of octopamine decreased with increasing baseline frequency. The percentage of increase in cycle frequency was inversely correlated with the baseline frequency of the rhythm. The first order exponential fit was done on all data pooled together $\left(R^{2}=0.8712 ; \mathrm{A} 1=\right.$ 5924309; $\mathrm{T} 1=-0.337$ )

The interesting possibility remains that the two release sites could have different release thresholds and that, in vivo, octopamine could be released selectively at one or both of the sites, adding a level of dynamic regulation to the effects of octopamine.

Octopamine is not the first neuromodulator to act at several sites to modulate the motor patterns of the STG. Red pigment concentrating hormone and proctolin likewise act on both anterior and STG sites to influence the STG motor patterns (Dickinson et al., 1993, 1997).

\section{Neuromodulator receptors on axons}

There are previous examples of neuromodulator receptors on axons. Axonal dopamine receptors activate a peripheral spike initiating zone in the PD axons in Homarus americanus (Bucher et al., 2003), and serotonin activates a peripheral spike initiating zone of the axon of the LG neuron in C. borealis (Meyrand et al., 1992). In these cases, modulation of the motor axons is likely to influence the strength and duration of muscle contraction (Meyrand et al., 1992; Bucher et al., 2003). One possibility for the function of the octopamine receptors on the axons of MCN5 might be to synchronize the activation of the axons, which project to the STG from the two sides of the animal. Relatively little is known about how bilaterally situated pairs of modulatory projection neurons are synchronized, and one way this could occur would be by direct actions on their axons at the first site at which the two neurons enter the stn.

\section{Will axonal receptors be common?}

In mammals, several classes of ionotropic receptors $\left(\mathrm{GABA}_{\mathrm{A}}\right.$, nicotinic acetylcholine) have been found on unmyelinated axons either in adult animals or early in development (Armett and Ritchie, 1960, 1961; Sakatani et al., 1991a,b,c; Lang et al., 2003; Verdier et al., 2003). Thus, modulation of axonal conduction may be more general than usually thought. Axonal receptors may turn out to provide a general mechanism for providing modulatory cross-talk between spatially diverse networks. Axons traveling through areas of local neuromodulatory release could be influenced by the chemical environment, thus gating, inhibiting, or enhancing the traffic through that site. In the case of the stomatogastric nervous system, clearly there is a local neuropil ideally positioned at the stn-son junction to facilitate bilateral coordination (Skiebe and Ganeshina, 2000). It is equally possible that axonal receptors in other circuits gate information passage and that axons may often be conditional rather than reliable conduits for carrying information.

\section{References}

Armett CJ, Ritchie JM (1960) The action of acetylcholine on conduction in mammalian non-myelinated fibres and its prevention by an anticholinesterase. J Physiol (Lond) 152:141-158.

Armett CJ, Ritchie JM (1961) The action of acetylcholine and some related substances on conduction in mammalian non-myelinated nerve fibres. J Physiol (Lond) 155:372-384.

Ayali A, Harris-Warrick RM (1999) Monoamine control of the pacemaker kernel and cycle frequency in the lobster pyloric network. J Neurosci 19:6712-6722.

Barker DL, Molinoff PB, Kravitz EA (1972) Octopamine in the lobster nervous system. Nat New Biol 236:61-62.

Barker DL, Kushner PD, Hooper NK (1979) Synthesis of dopamine and octopamine in the crustacean stomatogastric nervous system. Brain Res 161:99-113.

Blitz DM, Nusbaum MP (1997) Motor pattern selection via inhibition of parallel pathways. J Neurosci 17:4965-4975.

Blitz DM, Nusbaum MP (1999) Distinct functions for cotransmitters mediating motor pattern selection. J Neurosci 19:6774-6783.

Blitz DM, Christie AE, Coleman MJ, Norris BJ, Marder E, Nusbaum MP (1999) Different proctolin neurons elicit distinct motor patterns from a multifunctional neuronal network. J Neurosci 19:5449-5463.

Bucher DM, Thirumalai V, Marder E (2003) Axonal dopamine receptors activate peripheral spike initiation in a stomatogastric motor neuron. J Neurosci 23:6866-6875.

Callaway JC, Masinovsky B, Graubard K (1987) Co-localization of SCPBlike and FMRFamide-like immunoreactivities in crustacean nervous systems. Brain Res 405:295-304.

Coleman MJ, Nusbaum MP (1994) Functional consequences of compartmentalization of synaptic input. J Neurosci 14:6544-6552.

Coleman MJ, Nusbaum MP, Cournil I, Claiborne BJ (1992) Distribution of modulatory inputs to the stomatogastric ganglion of the crab, Cancer borealis. J Comp Neurol 325:581-594.

Dickinson P, Mecsas C, Hetling J, Terio K (1993) The neuropeptide red pigment concentrating hormone affects rhythmic pattern generation at multiple sites. J Neurophysiol 69:1475-1483.

Dickinson PS, Fairfield WP, Hetling JR, Hauptman J (1997) Neurotrans- 
mitter interactions in the stomatogastric system of the spiny lobster: one peptide alters the response of a central pattern generator to a second peptide. J Neurophysiol 77:599-610.

Flamm RE, Harris-Warrick RM (1986a) Aminergic modulation in lobster stomatogastric ganglion. I. Effects on motor pattern and activity of neurons within the pyloric circuit. J Neurophysiol 55:847-865.

Flamm RE, Harris-Warrick RM (1986b) Aminergic modulation in lobster stomatogastric ganglion. II. Target neurons of dopamine, octopamine, and serotonin within the pyloric circuit. J Neurophysiol 55:866-881.

Harris-Warrick RM, Kravitz EA (1984) Cellular mechanisms for modulation of posture by octopamine and serotonin in the lobster. J Neurosci 4:1976-1993.

Heinzel HG (1988) Gastric mill activity in the lobster. II. Proctolin and octopamine initiate and modulate chewing. J Neurophysiol 59:551-565.

Hooper SL, O’Neil MB, Wagner RJ, Ewer J, Golowasch J, Marder E (1986) The innervation of the pyloric region of the crab, Cancer borealis: homologous muscles in decapod species are differently innervated. J Comp Physiol [A] 159:227-240.

Kilman VL (1998) Multiple roles of neuromodulators throughout life: an anatomical study of the crustacean stomatogastric nervous system. $\mathrm{PhD}$ thesis, Brandeis University.

Kilman VL, Marder E (1996) Ultrastructure of the stomatogastric ganglion neuropil of the crab, Cancer borealis. J Comp Neurol 374:362-375.

Kilman VL, Fénelon V, Richards KS, Thirumalai V, Meyrand P, Marder E (1999) Sequential developmental acquisition of cotransmitters in identified sensory neurons of the stomatogastric nervous system of the lobsters, Homarus americanus and Homarus gammarus. J Comp Neurol 408:318-334.

Kobierski LA, Beltz BS, Trimmer BA, Kravitz EA (1987) FMRFamidelike peptides of Homarus americanus: distribution, immunocytochemical mapping, and ultrastructural localization in terminal varicosities. J Comp Neurol 266:1-15.

Kravitz EA, Huber R (2003) Aggression in invertebrates. Curr Opin Neurobiol 13:736-743.

Lang PM, Burgstahler R, Sippel W, Irnich D, Schlotter-Weigel B, Grafe P (2003) Characterization of neuronal nicotinic acetylcholine receptors in the membrane of unmyelinated human C-fiber axons by in vitro studies. J Neurophysiol 90:3295-3303.

Littleton JT, Bellen HJ, Perin MS (1993) Expression of synaptotagmin in Drosophila reveals transport and localization of synaptic vesicles to the synapse. Development 118:1077-1088.

Marder E, Bucher D (2001) Central pattern generators and the control of rhythmic movements. Curr Biol 11:R986-R996.

Marder E, Calabrese RL (1996) Principles of rhythmic motor pattern generation. Physiol Rev 76:687-717.

Marder E, Weimann JM (1992) Modulatory control of multiple task processing in the stomatogastric nervous system. In: Neurobiology of motor program selection (Kien J, McCrohan C, Winlow B, eds), pp 3-19. New York: Pergamon.

Marder E, Hooper SL, Siwicki KK (1986) Modulatory action and distribution of the neuropeptide proctolin in the crustacean stomatogastric nervous system. J Comp Neurol 243:454-467.

Marder E, Calabrese RL, Nusbaum MP, Trimmer B (1987) Distribution and partial characterization of FMRFamide-like peptides in the stomatogastric nervous systems of the rock crab, Cancer borealis, and the spiny lobster, Panulirus interruptus. J Comp Neurol 259:150-163.

Meyrand P, Weimann JM, Marder E (1992) Multiple axonal spike initiation zones in a motor neuron: serotonin activation. J Neurosci 12:2803-2812.

Mortin LI, Marder E (1991) Differential distribution of $\beta$-pigment dispersing hormone $(\beta-\mathrm{PDH})$-like immunoreactivity in the stomatogastric nervous system of five species of decapod crustaceans. Cell Tissue Res 265:19-33.

Nagy F, Cardi P, Cournil I (1994) A rhythmic modulatory gating system in the stomatogastric nervous system of Homarus gammarus. I. Pyloricrelated neurons in the commissural ganglia. J Neurophysiol 71:2477-2489.

Norris BJ, Coleman MJ, Nusbaum MP (1996) Pyloric motor pattern modification by a newly identified projection neuron in the crab stomatogastric nervous system. J Neurophysiol 75:97-108.

Nusbaum MP, Beenhakker MP (2002) A small-systems approach to motor pattern generation. Nature 417:343-350.

Nusbaum MP, Weimann JM, Golowasch J, Marder E (1992) Presynaptic control of modulatory fibers by their neural network targets. J Neurosci 12:2706-2714

Nusbaum MP, Blitz DM, Swensen AM, Wood D, Marder E (2001) The roles of co-transmission in neural network modulation. Trends Neurosci 24:146-154.

Peck JH, Nakanishi ST, Yaple R, Harris-Warrick RM (2001) Amine modulation of the transient potassium current in identified cells of the lobster stomatogastric ganglion. J Neurophysiol 86:2957-2965.

Roeder T (1999) Octopamine in invertebrates. Prog Neurobiol 59:533-561.

Russell DF (1976) Rhythmic excitatory inputs to the lobster stomatogastric ganglion. Brain Res 101:582-588.

Sakatani K, Hassan AZ, Ching W (1991a) Age-dependent extrasynaptic modulation of axonal conduction by exogenous and endogenous GABA in the rat optic nerve. Exp Neurol 114:307-314.

Sakatani K, Hassan AZ, Chesler M (1991b) GABA-sensitivity of dorsal column axons: an in vitro comparison between adult and neonatal rat spinal cords. Brain Res Dev Brain Res 61:139-142.

Sakatani K, Chesler M, Hassan AZ (1991c) GABA $_{A}$ receptors modulate axonal conduction in dorsal columns of neonatal rat spinal cord. Brain Res 542:273-279.

Schulz DJ, Robinson GE (1999) Biogenic amines and division of labor in honey bee colonies: behaviorally related changes in the antennal lobes and age-related changes in the mushroom bodies. J Comp Physiol [A] 184:481-488.

Schulz DJ, Barron AB, Robinson GE (2002) A role for octopamine in honey bee division of labor. Brain Behav Evol 60:350-359.

Skiebe P (1999) Allatostatin-like immunoreactivity within the stomatogastric nervous system and the pericardial organs of the crab Cancer pagurus, the lobster Homarus americanus, and the crayfish Cherax destructor and Procambarus clarkii. J Comp Neurol 403:85-105.

Skiebe P, Ganeshina O (2000) Synaptic neuropil in nerves of the crustacean stomatogastric nervous system: an immunocytochemical and electron microscopical study. J Comp Neurol 420:373-397.

Skiebe P, Wollenschlager T (2002) Putative neurohemal release zones in the stomatogastric nervous system of decapod crustaceans. J Comp Neurol 453:280-291

Skiebe P, Dietel C, Schmidt M (1999) Immunocytochemical localization of FLRFamide-, proctolin-, and CCAP-like peptides in the stomatogastric nervous system and neurohemal structures of the crayfish, Cherax destructor. J Comp Neurol 414:511-532.

Stevenson P, Meuser S (1997) Octopaminergic innervation and modulation of a locust flight steering muscle. J Exp Biol 200:633-642.

Verdier D, Lund JP, Kolta A (2003) GABAergic control of action potential propagation along axonal branches of mammalian sensory neurons. J Neurosci 23:2002-2007.

Weimann JM, Meyrand P, Marder E (1991) Neurons that form multiple pattern generators: identification and multiple activity patterns of gastric/ pyloric neurons in the crab stomatogastric system. J Neurophysiol 65:111-122.

Weimann JM, Skiebe P, Heinzel H-G, Soto C, Kopell N, Jorge-Rivera JC, Marder E (1997) Modulation of oscillator interactions in the crab stomatogastric ganglion by crustacean cardioactive peptide. J Neurosci 17: $1748-1760$. 